\title{
RISCOS HEPÁTICOS PROVENIENTES DA AUTOMEDICAÇÃO
}

\section{ARTIGO DE REVISÃO}

CONCEIÇÃO, Mirela Cristina Chaves ${ }^{1}$

ALMEIDA, Isadora Barbosa de ${ }^{2}$

XISCATTI, Valéria Scarlleth Costa ${ }^{3}$

PEREIRA, Domingos Magno Santos ${ }^{4}$

FIGUEIREDO, Cristiane Santos Silva e Silva ${ }^{5}$

CONCEIÇÃO, Mirela Cristina Chaves. Et al. Riscos hepáticos provenientes da automedicação. Revista Científica Multidisciplinar Núcleo do Conhecimento. Ano 05, Ed. 11, Vol. 01, pp. 109-118. Novembro de 2020. ISSN: 2448-0959, Link de acesso:

\section{RESUMO}

A automedicação se caracteriza pela administração de substâncias medicamentosas, para aliviar sintomas ou tratar patologias, sem prescrição médica ou orientação de um profissional da saúde, o que pode comprometer a função do fígado ou causar um dano hepático mais grave. O objetivo deste trabalho foi analisar a incidência de automedicação e seus fatores de riscos ao fígado. Foi realizado uma revisão de literatura, através de buscas em revistas eletrônicas disponíveis nas bases de dados Scientific Eletronic Library Online (SciELO), Revista Eletrônica Biociências, Biotecnologia e Saúde, PubMed e Google Academic, em artigos publicados entre os

\footnotetext{
${ }^{1}$ Graduanda em Biomedicina pela Universidade Ceuma.

${ }^{2}$ Graduanda em Biomedicina, pela Universidade Ceuma.

${ }^{3}$ Graduanda em Biomedicina, pela Universidade Ceuma.

${ }^{4}$ Docente do Curso de Biomedicina, pela Universidade Ceuma.

${ }^{5}$ Docente do Curso de Biomedicina, pela Universidade Ceuma.
} 
anos de 2015 a 2020. Após análise dos artigos incluídos na revisão, os resultados contribuem para o perfil de risco sobre a hepatotoxidade dos medicamentos utilizados de forma irracional. Portanto, tornam-se necessárias medidas preventivas de modo a contribuir com a redução do consumo desenfreado e ao mesmo tempo que seja incentivada a população a procurar um profissional da saúde.

Palavras-chave: Automedicação, lesão hepática, hepatite medicamentosa.

\section{INTRODUÇÃO}

A automedicação é uma prática comum e envolve principalmente o uso de medicamentos isentos de prescrição médica ou aconselhamento de um profissional da saúde, caracterizando-se, pela iniciativa de um doente, ou de seu responsável, na intenção de ingerir algum produto que acredita lhe ser eficaz no tratamento da doença ou solução para o alívio imediato de alguns sintomas (FURLAN et al., 2015).

Vista, na maioria das vezes, como um ato de necessidade, a automedicação é considerada como problema de saúde pública mundial, presente desde as sociedades primitivas, quando homens produziam e utilizavam substâncias de origem animal e plantas medicinais, associadas com ritos mágicos e crenças, visando à cura de patologias (FURLAN et al., 2015).

O Sistema Único de Saúde (SUS) é uma referência mundial, mas existem falhas quanto sua administração quando se refere a assistência médica pública, que induz a difusão desta prática, além da facilidade de acesso a medicamentos em farmácias e supermercados e o acúmulo de medicamentos nas residências, gerando um verdadeiro arsenal terapêutico, que também são fatores complementares e primordiais para o consumo (ALENCAR et al., 2019).

No Brasil, existem um total de 66 diferentes compostos, os quais estão divididos em 21 anti-inflamatórios esteroidais, ou glicocorticoides e os outros 45 são da classe de anti-inflamatórios não esteroides (AINES), como o paracetamol, ácido salicílico, ibuprofeno, e o diclofenaco de sódio, que apresenta elevação dos níveis de enzimas hepáticas em exames de sangue (LIMA et al., 2018). 
A maioria dos danos ocasionados às células do fígado é provocada por substâncias químicas que possuem metabólitos capazes de causar alterações dos sistemas enzimáticos e desarranjo estrutural metabólico. Os medicamentos podem ser convertidos em formas inativas no fígado, ou até mesmo ativados e convertidos a substâncias nocivas pela transformação hepática (LIMA et al., 2018).

Geralmente, os medicamentos utilizados nessa prática, são os liberados para venda sem receita médica, chamados over-the-counter (OTC), como os AINEs, mais determinados por mecanismo idiossincrático do que por efeito tóxico direto e que possuem efeito teto, ou seja, a administração de doses maiores não aumenta a eficácia terapêutica, mas causa um crescimento de efeitos adversos (DOS REIS et al., 2017).

O dano hepático induzido por droga, também conhecido como hepatite medicamentosa, é uma patologia comum do fígado, que se manifesta normalmente entre um e 90 dias após a administração do medicamento em doses habituais e pode variar desde alterações assintomáticas das enzimas hepáticas ou até mesmo Insuficiência hepática fulminante e em casos de quadro clínico mais grave, pode ocasionar o óbito (DE CASTRO BARROS et al., 2019).

Sendo o fígado, o principal metabolizador corporal, os três padrões básicos de lesão são classificados em hepatocelular, colestática e mista. Considerada a mais frequente, a lesão hepatocelular, onde há alterações dos biomarcadores utilizados na triagem básica de disfunção hepática. São eles: o aspartato amino transferase (AST) e alanina amino transferase (ALT), que quando alterados levará ao aumento de bilirrubina (direta), enzimas fosfatase alcalina e gama glutamil transferase (gama-GT) e que se apresenta de forma aguda, diferente do tipo colestática e mista, pois se manifestam de forma crônica (BLATT et al., 2016).

Apesar da indústria farmacêutica ter avançado significativamente, ainda não foi possível obter fármacos que possam proteger completamente o fígado, promover a regeneração e estimulação hepática e garantir ao mesmo tempo a sua eficácia. Desta forma, é de grande importância reconhecer os riscos da automedicação, promovendo 
o uso racional de medicamentos e enfatizar a importância do acompanhamento de um profissional da saúde (MARMITT et al., 2016).

Dada a relevância desta temática, o artigo objetivou analisar e apresentar os efeitos da automedicação e os fatores de riscos que podem levar a disfunções hepáticas.

\section{METODOLOGIA}

O trabalho desenvolvido trata-se de uma revisão de literatura, tendo como tema de pesquisa Riscos Hepáticos provenientes da Automedicação. Realizou-se busca da literatura nas bases de dados científicos, Scientific Eletronic Library Online (SciELO), Revista Eletrônica Biociências, Biotecnologia e Saúde, Google Academic, a fim de analisar os efeitos da automedicação e seus fatores de riscos ao fígado. Foram utilizados 21 artigos nacionais e 4 internacionais, disponíveis online em texto completo. Os seguintes descritores aplicados: Automedicação, Hepatite medicamentosa, Lesão hepática. Para a seleção das fontes, foram consideradas como critério de inclusão os artigos publicados entre os anos de 2015 a 2020, que abordassem a automedicação e consequentemente os seus riscos ao fígado. Foram excluídos os artigos que não condizem com a linha de pesquisa, da mesma forma artigos repetidos nas bases de dados.

\section{RESULTADOS E DISCUSSÕES}

O fígado é o maior, mais pesado e vascularizado órgão interno do corpo humano, e a sua atividade está relacionada a processos de metabolização e desintoxicação de agentes terapêuticos. Desta forma, o metabolismo de fármacos ocorre através das enzimas microssomais, no reticulo endoplasmático de células hepáticas e por ser o principal órgão envolvido nesse processo, o fígado estar suscetível a danos por alguns medicamentos (DOS REIS et al., 2017; TERRES et al., 2015).

Nas classificações farmacológicas mais prováveis a uma toxidade hepática, destacam-se os antibióticos, anticonvulsivantes e os anti-inflamatórios não esteróides (AINES), frequentemente associado como importante grupo causador de disfunções 
hepáticas aguda, em casos de abuso ou superdosagem (CANO; CIFUENTES, AMARILES, 2017).

Dentre os medicamentos possivelmente hepatotóxicos tem-se o paracetamol, de nome químico $\mathrm{N}$-acetil-p-aminofenol, também conhecido como acetaminofeno, tem sido amplamente associado a intoxicação hepática, sendo o medicamento mais auto administrado no Brasil, seguido da dipirona (TITTARELLI et al., 2017). Quando administrado em dose terapêutica (dependendo do peso corporal, na proporção $\mathrm{mg} / \mathrm{kg}$ ), é considerado um "medicamento seguro" (ZAKARIA et al., 2017). Entretanto, em casos de superdosagens, a ponto de overdose, há uma redução nos níveis de glutationa (GSH) hepática, e produção em excesso de N-acetil-p-benzo-quinona imina (NAPQI), metabólito tóxico altamente reativo, causando grave hepatotoxidade e consequentemente insuficiência hepática aguda (KAWAKAMI et al., 2017; BORGES et al., 2018).

Já o diclofenaco é um fármaco inibidor da ciclooxigenase (COX) com propriedades anti-inflamatória, antitérmica, analgésica e menor agregação plaquetária comparado a outros AINEs (COSTA et al., 2020). A sua transformação em substância tóxica, está associada ao ácido glicurônico, seu principal metabólito reativo e o uso crônico de diclofenaco pode levar à uma reação inflamatória do fígado denominada hepatite medicamentosa e quando associado a vitaminas $B 1, B 6$ e $B 12$, tem efeito potencializado (QUEZADA et al., 2018, PEDROSO; BATISTA, 2017).

Tem-se ainda a Nimesulida que é um fármaco pertencente à classe dos AINES e é comumente utilizada pela população de forma inadvertida. A Organização Mundial de Saúde notificou que a nimesulida induz uma proporção significativa de formas graves de toxicidade hepática em relação a outros anti-inflamatórios não esteróides (MENEGOI et al., 2019). Os mecanismos pelos quais esse tipo de reação adversa pode ser desenvolvida ainda não foram completamente definidos, no entanto, tem sido associada a lesões hepáticas como hepatite aguda medicamentosa, ocorrendo na maioria das vezes, dentro da dose terapêutica. (BERNARDES et al., 2015). 
O ácido acetilsalicílico ou aspirina (AAS) é um dos fármacos mais utilizados no mundo, sua toxicidade hepática depende da dose e sua concentração é superior a 25 mg/100 $\mathrm{mL}$. O mecanismo de lesão hepática pode ser devido ao acúmulo de metabólitos tóxicos, ácido salicílico, ácido úrico e ácido glicurônico fenólico salicílico, e aumento das enzimas hepáticas que danificam as membranas celulares do fígado (LIMA et al., 2018).

O ibuprofeno é um antiinflamatório não esteroidal (AINE), que pertence ao subgrupo dos derivados do ácido propiônico e possui efeitos analgésicos, antiinflamatórios e antipiréticos. Existem poucos casos de lesão hepática induzida por esse medicamento, principalmente se não houver sinais ou sintomas sistêmicos e a frequência de hepatotoxicidade idiossincrática for pequena. No entanto, em doses altas ou superiores à terapêutica, pode causar dano hepático dependente da dose (PRADO et al., 2018).A partir do exposto acima entende-se que as lesões são classificadas de acordo com os níveis de hepatotoxicidade, ou seja com a manifestação clínica do paciente, em hepatocelular (definida pelas taxas de alanina amino transferase (ALT), colestática (definida pela atividade sérica da fosfatase alcalina (ALP), e mista que envolvendo taxas de ALT e ALP (GOMES et al., 2019).

Essas alterações podem ser observadas a partir das dosagens séricas laboratoriais que avaliam a função hepática e consiste na realização de testes que dosam a atividade de enzimas presentes no fígado. Além disso pode-se utilizar a biópsia, que auxilia na diferenciação dos diversos tipos de hepatite, pois a caracterização do tipo de lesão hepática é importante tanto para o diagnóstico como para o prognóstico. Sendo que a suspensão do medicamento é o primeiro passo para prevenir ou minimizar lesões (GODOY et al., 2017).

\section{CONCLUSÃO}

As facilidades no consumo favorecem a prática da automedicação, por isso a importância de se avaliar o funcionamento hepático durante um tratamento farmacológico. Pois, as reações podem ser imprevisíveis, algumas graves e de prognóstico reservado (baixa probabilidade de sobrevida com dignidade). Diante do 
exposto, há necessidade vigente em diminuir essa prática, através da informação à população sobre o uso racional de medicamentos, considerando a qualidade, a segurança e a eficácia dos fármacos como também incentivar a procura e o acesso ao profissional de saúde.

\section{REFERÊNCIAS}

ALENCAR, Waleska Torres et al. FATORES QUE LEVAM À PRÁTICA DA AUTOMEDICAÇÃO: REVISÃO INTEGRATIVA. CDD-614, p. 93, 2019.

BERNARDES, S. S. et al. Nimesulide-induced fatal acute liver failure in an elderly woman with metastatic biliary adenocarcinoma. A case report. São Paulo Medical Journal, v. 133, n. 4, p. 371-376, 2015.

BLATT, Carine Raquel; BECKER, Matheus William; LUNARDELI, Michele John Muller. Lesão hepática induzida por medicamentos: qual o papel do farmacêutico clínico. Revista Brasileira de Farmácia Hospitalar e Serviços de Saúde, v. 7, n. 4, 2016.

BORGES, R. S. et al. Avanços químicos no planejamento e desenvolvimento do paracetamol. Revista Química Nova, v. 41, n. 10, p. 1167-1177, 2018.

CANO, Alejandra; CIFUENTES, Laura; AMARILES, Pedro. Revisão estruturada da literatura sobre toxicidade hepática causada por medicamentos. Jornal Colombiano de Gastroenterologia , v. 32, n. 4, pág. 337-348, 2017.

COSTA, Ingrid Andresa Fernandes; DE SOUSA OLIVEIRA, Fernando. FÁRMACOS HEPATOTÓXICOS E HEPATOPROTETORES: UMA REVISÃO DE LITERATURA. Journal of Biology \& Pharmacy and Agricultural Management, v. 17, n. 1, 2020.

DE CASTRO BARROS, Anne Joyce et al. LESÃO HEPÁTICA INDUZIDA POR MEDICAMENTOS E O PAPEL DO FARMACÊUTICO NO SEU MANEJO CLÍNICO. Mostra Científica da Farmácia, v. 5, 2019. 
DOS REIS, Ana Rosa Muniz; PAVANELLI, Mariana Felgueira; DE SOUZA BRAGA, Lais. Hepatotoxicidade pelo uso de paracetamol: uma revisão da literatura. Revista Iniciare, v. 2, n. 1, 2017.

FURLAN, Bruna Tamazzi. Os efeitos adversos e riscos associados à automedicação: avaliação do conhecimento da população de Americana, SP e região. Revista de Trabalhos Acadêmicos da FAM, v. 1, n. 1, 2016.

GLINKA, Caroline; DE MORAIS RIBEIRO, Camila Nunes. O PAPEL DO PARACETAMOL NA HEPATITE MEDICAMENTOSA. REVISTA ELETRÔNICA BIOCIÊNCIAS, BIOTECNOLOGIA E SAÚDE, v. 11, n. 21, p. 46-54, 2018.

GOMES, Bianca Thais Lemos et al. AVALIAÇÃO DA FUNÇÃO HEPÁTICA: UMA REVISÃO BIBLIOGRÁFICA. Mostra Científica em Biomedicina, v. 4, n. 1, 2019.

GODOY, Yasna Patrícia Aguilera et al. AVALIAÇÃO CELULAR E FUNCIONAL DO FÍGADO ESTIMULADA POR LASER DE BAIXA POTÊNCIA NO TRANSOPERATÓRIO. ABCD. Arquivos Brasileiros de Cirurgia Digestiva (São Paulo), v. 30, n. 2, p. 122-126, 2017.

KAWAKAMI, Kayoko et al. Hepatoprotective effects of rice-derived peptides against acetaminophen-induced damage in mice. Journal of Clinical Biochemistry and Nutrition, p. 16-44, 2017.

LIMA, Alana Silva; DE OLIVEIRA ALVIM, Haline Gerica. Revisão sobre Antiinflamatórios Não-Esteroidais: Ácido Acetilsalicílico. Revista de Iniciação Científica e Extensão, v. 1, n. Esp, p. 169-174, 2018.

MARMITT, Diorge Jônatas et al. Potencial hepatoprotetor das plantas medicinais da renisus: revisão sistemática. Revista de Atenção à Saúde, v. 14, n. 49, p. 84-91, 2016

MENEGOI, Yasmin Luiz Fonseca. Complicações do uso da nimesulida-revisão de literatura. Revista Brasileira de Odontologia, v. 76, p. 99, 2019. 
MIRANDA, Laura Pacheco. Risco da automedicação: informaçao em prol da mudança de hábito. Acervo da Iniciação Científica, n. 2, 2014.

PRADO, NÍLIA MARIA DE BRITO LIMA et al. Hepatotoxicidade induzida por medicamento em um paciente ambulatorial: relato de caso. Revista Brasileira de Farmácia Hospitalar e Serviços de Saúde, v. 9, n. 1, 2018.

PEDROSO, Caroline Ribeiro; BATISTA, Francislene Lavor. O USO INDISCRIMINADO DOS ANTI-INFLAMATÓRIOS NÃO ESTEROIDAIS. SAÚDE \& CIÊNCIA EM AÇÃO, v. 3, n. 1, p. 48-69, 2017.

PINHEIRO, Jossana Alves dos Santos et al. Hepatotoxicidade de plantas medicinais e produtos herbais. Referências em Saúde da Faculdade Estácio de Sá de GoiásRRS-FESGO, v. 3, n. 1, 2020.

POSTIGUILHONE, Tarcia Mirian; LOPES, Daiene Barbosa; RAMPELOTTO, Geórgia Figueira. HEPATITE MEDICAMENTOSA E A ENFERMAGEM DE FORMA INTERDISCIPLINAR. Revista das Semanas Acadêmicas, v. 4, n. 6, 2017.

QUEZADA, Diana Vanessa Lagos et al. Reações sistêmicas causadas pela toxicidade do diclofenaco. Revista Científica da Escola Universitária de Ciências da Saúde , v. 5 , n. 1 pág. 41-49, 2018.

SHAHNAZARIAN Vahe, RAMAI Daryl, REDDY Madhavi. A Rare Case of Ibuprofeninduced Acute Liver Injury. Cureus. 2018.

TERRES, D. R. Potencial toxicológico de medicamento de venda livre: ênfase no paracetamol. FACIDER Revista Científica, v. 1, n. 8, p. 1-15, 2015.

TITTARELLI, R.; PELLEGRINI, M.; SCARPELLINI, M.G.; MARINELLI, E.; BRU TI, V.; DI LUCA, N.M.; BUSARDÒ, F.P.; ZAAMI, S. Hepatotoxicity of paracetamol and related fatalities. European Review for Medical and Pharmacological Sciences, p. 95-101, 2017. 
ZAKARIA, Zainul Amiruddin et al. Methanol extract of Dicranopteris linearis L. leaves impedes acetaminophen-induced liver intoxication partly by enhancing the endogenous antioxidant system. BMC complementary and alternative medicine, $\mathrm{v}$. 17, n. 1, p. 271, 2017.

Enviado: Outubro, 2020.

Aprovado, Novembro, 2020. 